\title{
DISTRIBUIÇÃO GEOGRÁFICA E COMPOSIÇÃO QUÍMICA DE CHAPÉU DE COURO (Echinodorus spp.) NO RIO GRANDE DO SUL ${ }^{1}$
}

\author{
GEOGRAPHICAL DISTRIBUTION AND CHEMICAL COMPOSITION OF \\ “CHAPÉU DE COURO” (Echinodorus spp.) IN THE \\ RIO GRANDE DO SUL STATE, BRAZIL
}

\author{
Gilberto Antonio Peripolli Bevilaqua ${ }^{2}$ Jorge Luis Nedel $^{3}$ \\ José Angelo Zuanazzi ${ }^{4}$ Claudia Tatiane Correa ${ }^{5}$
}

RESUMO

Com o objetivo de descrever a variabilidade genética e química da planta medicinal chapéu de couro (Echinodorus grandiflorus Mich. e outras espécies) existente no Rio Grande do Sul, foram coletadas plantas em 16 diferentes localidades $e$ transplantadas para uma área experimental na Universidade Federal de Pelotas, em Pelotas-RS. As plantas foram cultivadas em planossolo alagado no inverno e com irrigação suplementar quando houve umidade insuficiente no solo. A adubação das plantas foi calcáreo, cinza de casca de arroz e vermicomposto. As folhas e sementes foram colhidas na primavera e verão. Foi procedida a descrição dos ecotipos, através dos parâmetros fenológicos: início da brotação, vigor da brotação, florescimento, antese, maturação das sementes e, agronômicos: resistência ao frio e à insolação, competição com plantas daninhas e peso da matéria seca foliar, bem como uma análise dos compostos químicos majoritários nas folhas. As avaliações permitiram concluir que: 1- a espécie predominante no Rio Grande do Sul é a Echinodorus grandiflorus; 2 - os ecotipos de Cruz Alta e de São Gabriel são recomendados para cultivo como precocidade $e$ produção de matéria seca; 3 - os ecotipos de Arroio Grande e Jaguarão são recomendados para cultivo pela composição química mais numerosa.

Palavras-chave: Echinodorus, fenologia, cromatografia, variabilidade, cultivo.

\section{SUMMARY}

The aim of this research work was to describe the genetic and chemical variability of the medicinal specie "chapéu de couro" (Echinodorus grandiflorus and other species), which is found in Rio Grande do Sul State, Brazil. The plants had been collected at sixteen different sites and planted again in an experimental area at the Federal University of Pelotas (UFPel), in the town of Pelotas-RS. The plants have grown in waterlands, by keeping them underwater during the winter and adding water when the soil was dry. The plants have been fed up with lime, ash of rice waste and vermcomposite. The leaves and the seeds have been collected during spring and summer. The phenology of the different material has been observed to proceed the botanical and physiological description of ecotypes, through field parameters and in the experimental area. The chemical composition of the major chemical substances in the leaves of both native and non native plants was also analyzed. The evaluation led to conclude that: 1- the vailing specie in Rio Grande do Sul State is Echinodorus grandiflorus; 2 - the ecotypes from Cruz Alta and São Gabriel are prefered for cropping due to their early and dry matter production; 3 - the ecotypes from Arroio Grande and Jaguarão are prefered for cropping due to your rich chemical composition.

Key words: phenology, Echinodorus, chromatography, variability, cropping.

\section{INTRODUÇÃO}

O gênero Echinodorus pertence à família Alismataceae e ocorre dos EUA até a Argentina, sendo restrito ao hemisfério ocidental. As plantas dessa família são acaulescentes e ocorrem em pântanos ou áreas alagadas, sendo reconhecidas pela

\footnotetext{
${ }^{1}$ Financiado com recursos da Fapergs. Km 174, CP 451, 99001-970, Passo Fundo, RS. Autor para correspondência.

${ }^{3}$ Engenheiro agrônomo, Professor Titular, Depto de Fitotecnia, UFPEL.

${ }^{4}$ Farmacêutico bioquímico, Professor Adjunto, Departamento de Produção de Matéria-Prima, UFRGS.

${ }^{5}$ Farmacêutica bioquímica, estagiária do Departamento de Produção de Matéria-Prima, UFRGS.
}

${ }^{2}$ Engenheiro agrônomo, Professor Adjunto, Curso de Ecologia, UCPEL, Bolsista CNPq, bevilaq@cnpt.embrapa.br, Rodovia BR 285,

Recebido para publicação em 14.06.99. Aprovado em 02.08.00 
seiva leitosa e pelos frutos que são aquênios. As flores de cor branca são perfeitas ou imperfeitas, como no gênero Sagittaria (HAYNES \& HOLMNIELSEN,1994). A planta foi descrita por CORREA JUNIOR $\boldsymbol{e}$ t al. (1991) e SILVA JUNIOR et al. (1994) como uma erva aquática de caule triangular e glabro; folhas longo-pecioladas, ovadas a cordiformes; de consistência coriácea; grandes, eretas e flutuantes; a espécie mais comum é a Echinodorus grandiflorus.

O chapéu de couro é uma planta de grande expressão na medicina popular, no entanto, com pouquíssimas informações sobre cultivo, variedades existentes e fenologia visando a um melhor aproveitamento e conservação da planta. Segundo CORREA (1984) e ALMEIDA (1993), a espécie tem propriedades adstringentes e é usada no combate a inflamações da garganta e feridas que não cicatrizam. Segundo SILVA JUNIOR et al. (1994), a planta é ornamental, própria para chafarizes, pequenos lagos artificiais e aquários. $\mathrm{O}$ extrativismo dessa espécie, em algumas regiões, predispõe-na a riscos de extinção local ou regional, devido as suas grandes virtudes terapêuticas (SIMÕES $\boldsymbol{e t}$ al., 1995).

Os principais grupos de princípios ativos identificados na planta são alcalóides, glicídeos, óleos essenciais, ácidos orgânicos, heterosídeos e taninos (CORREA JUNIOR $\boldsymbol{e}$ t $\boldsymbol{a l}$., 1991). MANNS \& HARTMANN (1988) concluíram que o princípio ativo da planta é um diterpeno, chamado de "echinodol" (ácido echinóico), obtido através de extração metanólica de folhas secas da planta, à baixa temperatura. Mais recentemente, TANAKA et al. (1997) concluíram que o ácido equinóico é o metabólito secundário predominante no extrato etanólico dessa planta.

Nos programas de pesquisa com plantas medicinais, as espécies em risco de extinção devem ser preferenciais, assim como aquelas com ampla capacidade fitoterápica. O chapéu de couro (Echinodorus macrophyllus) junto com Pfaffia paniculata (fáfia), Tabebuia ipe (Ipê-roxo) e Polygonum hidropiperoides (erva de bicho) foram as espécies que apresentaram os maiores volumes de material exportado no último ano (SILVA JUNIOR \& VIZZOTO, 1996). Conforme CASTRO \& CHEMALE (1995), para a maioria das espécies medicinais, não se conhecem as variedades existentes e a propagação dos materiais é feita de forma assexuada, sendo, portanto, materiais geneticamente idênticos.

A montagem de bancos de germoplasma e sua importância foram colocadas por vários autores. ARORA \& ENGELS (1993), FOSTER (1993) e VIEIRA \& SKORUPA (1993) apresentam alternati- vas para pesquisa e uso de recursos genéticos de espécies medicinais, relacionando a erosão genética e conservação desses recursos. SILVA JUNIOR $\boldsymbol{e t}$ al. (1994) indicam algumas metas a serem alcançadas nas pesquisas em plantas medicinais, iniciando com a instalação de unidades de observação, como coleções e bancos de germoplasma, para observar as características fenológicas e morfológicas das espécies; posteriormente, deve-se estudar os modos de propagação das espécies.

A análise da composição química das plantas possui uma dupla importância. Torna-se essencial para efeitos de comercialização do material, identificando os materiais mais atrativos à indústria farmacéutica, além de auxiliar aos produtores na seleção de genótipos mais eficientes em termos fitoterápicos. SILVA JUNIOR \& VIZZOTO (1996) concluíram que fatores ambientais como a fertilidade e umidade do solo, $\mathrm{pH}$, temperatura e estações climáticas podem influir decisivamente na expressão de determinados princípios ativos.

Os objetivos do trabalho foram: a) observar a fenologia do chapéu de couro em área experimental; b) analisar a quantidade dos princípios ativos de importância medicinal através de cromatografia; c) verificar o efeito do cultivo em características agronômicas e na composição química das folhas e sementes.

\section{MATERIAL E MÉTODOS}

O trabalho de pesquisa foi realizado na Universidade Federal de Pelotas, em área experimental pertencente ao Departamento de Fitotecnia. O solo é um planossolo pertencente à unidade Pelotas, com as seguintes características físico-químicas: pH 5,5; K 35mg/dm $\mathrm{dm}^{3}$ P $0,9 \mathrm{mg} / \mathrm{dm}^{3}$; argila $20 \%$, matéria orgânica $2 \%$. A área experimental localizouse ao lado de um açude, onde foram feitos cordões de terra que garantiam uma boa retenção de água.

\section{Coleta e cultivo}

Foram identificados e coletados ecotipos da planta em várias áreas de ocorrência natural no Rio Grande do Sul (Tabela 1), entre novembro de 1996 a fevereiro de 1997, e transplantadas para a área experimental. A reprodução do material foi feita via secção do rizoma, com 3 mudas de cada planta, conforme SILVA JUNIOR et al. (1994). A adubação da área experimental foi feita com base no arroz irrigado (Oryza sativa L.), com $3,5 \mathrm{t}_{\mathrm{ha}}{ }^{-1}$ de calcário, 4t.ha ${ }^{-1}$ de cinza de casca de arroz incinerada e 1t.ha ${ }^{-1}$ de vermicomposto, em duas épocas do ano: no final da fase vegetativa e início da brotação. Foi 
Tabela 1- Procedência, data de coleta, gênero e espécie dos 16 ecotipos de chapéu de couro (Echinodorus spp.) analisados no experimento. Pelotas, RS, 1998.

\begin{tabular}{|c|c|c|c|}
\hline Ecotipo & Procedência & $\begin{array}{c}\text { Data de } \\
\text { coleta }\end{array}$ & Gênero e espécie ${ }^{1}$ \\
\hline 1 & Camaquã, RS & $11 / 96$ & Echinodorus grandiflorus \\
\hline 2 & Porto Alegre, RS & $11 / 96$ & Echinodorus grandiflorus \\
\hline 3 & Santo Augusto, RS & $12 / 96$ & Echinodorus grandiflorus \\
\hline 4 & Cruz Alta, RS & $02 / 97$ & Echinodorus \\
\hline 5 & Passo Fundo, RS & $10 / 96$ & Echinodorus \\
\hline 6 & São Gabriel, RS & $12 / 96$ & Echinodorus grandiflorus \\
\hline 7 & São Vicente, RS & $01 / 97$ & Sagittaria latifolia \\
\hline 8 & Sobradinho, RS & $12 / 96$ & Echinodorus grandiflorus \\
\hline 9 & Santa Maria, RS & $12 / 96$ & Echinodorus grandiflorus \\
\hline 10 & Dom Pedrito, RS & $12 / 96$ & Echinodorus grandiflorus \\
\hline 11 & Alegrete, RS & $12 / 96$ & Echinodorus grandiflorus \\
\hline 12 & Pelotas, RS & $11 / 96$ & Echinodorus uruguayensis \\
\hline 13 & Arroio Grande, RS & $11 / 96$ & Echinodorus grandiflorus \\
\hline 14 & Jaguarão, RS & $12 / 96$ & Echinodorus grandiflorus \\
\hline 15 & Mata, RS & $12 / 96$ & Echinodorus grandiflorus \\
\hline 16 & Torres, RS & $03 / 98$ & Echinodorus \\
\hline
\end{tabular}

${ }^{1}$ Identificação efetuada por Marcos Sobral (UFRGS), segundo HAYNES \& HOLM-NIELSEN (1994).

utilizada irrigação tão logo foi constatada umidade do solo inferior à capacidade de campo (cerca de $20 \%$ ).

\section{Descrição dos ecotipos}

Observaram-se características fenológicas e agronômicas, seguindo a metodologia de SILVA (1993):

a) características fenológicas: início da brotação, período em dias entre o plantio das mudas e o aparecimento das folhas; início da floração, dias do plantio até a emissão da panícula; antese, dias entre o plantio e a abertura de $50 \%$ das flores; maturação das sementes, dias entre o plantio e a colheita das sementes.

b) características agronômicas: resistência ao frio, avaliado em 6 períodos, entre abril e julho, com uma escala com valores de 0 a 3 , onde: 0 - necrose severa das folhas maduras e novas e paralisação do crescimento, 1 - necrose das folhas maduras e mais novas, 2- necrose das folhas maduras, 3 - pequena necrose nos bordos de folhas maduras; resistência à insolação, avaliado em três períodos, em dezembro e janeiro, com as parcelas totalmente isentas de plantas invasoras, com a escala: 0 - necrose severa das folhas maduras e novas e paralisação do crescimento , 1 - necrose severa das folhas maduras e pequena nas folhas novas, 2 - necrose das folhas maduras, 3 necrose dos bordos das folhas maduras; competição com plantas daninhas, avaliado na primavera em 3 períodos imediatamente antes de se proceder a capina das parcelas, com a seguinte escala de avaliação: 0 - restrição severa do crescimento com folhas muita pequenas, 1 - restrição severa com folhas de tamanho médio e em pequeno número, 2 - restrição pequena com folhas de tamanho normal em pequeno número, 3 - folhas de tamanho normal e em grande número; pegamento avaliado em duas épocas, 30 e 60 dias pós plantio na escala: 0 - secamento total da planta e ausência de brotação, 1 - secamento das folhas maduras sem brotação, 2 - secamento das folhas maduras com pequena brotação; 3 - pouco secamento e folhas novas já visíveis $(2 \mathrm{~cm}$ ou mais); vigor da brotação, avaliado pelo número de folhas por inflorescência; peso da matéria seca (PMS) foram colhidas 5 folhas de cada ecotipo e secas em estufa a $40^{\circ} \mathrm{C}$ durante 3 dias, foram pesadas e o resultado expresso em $\mathrm{g} /$ folha.

\section{Análise dos padrões fitoquímicos}

Foram avaliados os ecotipos através da análise dos compostos químicos majoritários nas folhas. A colheita das folhas, na área de cultivo e em seu habitat natural, iniciou-se em 30/09/97, quando as plantas iniciaram a floração, conforme CASTRO \& CHEMALE (1995). Após colhidas, as folhas foram colocadas em sacos de papel e imediatamente colocadas em estufa a $40^{\circ} \mathrm{C}$ até a completa secagem, observada pelo esfarelamento da folha, conforme OLIVEIRA \& AKISSUE (1989). Após a secagem, as amostras foram moídas e colocadas em solvente etanol comercial. Foram concentradas e fracionadas por diferentes polaridades de solvente (diclorometano). O adsorvente utilizado foi gel de sílica (GF 254) da marca Merck. Os métodos de revelação foram luz ultravioleta $366 \eta m$ e vanilina sulfúrica, utilizando a metodologia descrita por STAHL (1969).

\section{Análise estatística}

A regularidade das observações foram semanais ou diárias em épocas críticas como início da brotação e antese. Os parâmetros resistência à insolação, resistência ao frio, competição com ervas daninhas e pegamento foram analisados por correlação simples e desvio padrão. Os demais parâmetros classificaram os ecotipos pelo desvio padrão, seguindo o critério de valores superiores, sendo aqueles cujo valor estivesse abaixo ou acima do valor da média, menos um desvio padrão, dependendo do caso. As procedências constituíram-se em trata- 
mento, sendo cada muda considerada uma repetição do trabalho.

\section{RESULTADOS E DISCUSSÃO}

\section{a) Descrição dos ecotipos}

Conforme observa-se na tabela 1 , dos 16 ecotipos que foram trabalhados neste estudo, apenas um não era do gênero Echinodorus, pertencendo ao gênero Sagittaria (usada para estudos preliminares). Encontrou-se que a espécie predominante, na maioria das procedências, era da espécie Echinodorus grandiflorus, confirmando informações de CORREA JUNIOR $\boldsymbol{e t}$ al. (1991), sendo que apenas o ecotipo proveniente de Pelotas pertence à espécie E. uruguayensis. No entanto, segundo HAYNES \& HOLM-NIELSEN (1994), ocorrem 6 espécies desse gênero na região sul do Brasil.

Todos os ecotipos apresentaram dormência no inverno, com suscetibilidade variável às baixas temperaturas e geada. De uma maneira geral, a espécie é bem resistente às baixas temperaturas, principalmente quando as plantas estão submersas (HAYNES \& HOLM-NIELSEN, 1994). Os ecotipos 6 e 12, provenientes de São Gabriel e Pelotas, RS, respectivamente, mostraram-se significativamente superiores à média das amostras na avaliação de resistência ao frio (Tabela 2). Por outro lado, os

Tabela 2 - Pegamento, resistência ao frio, resistência à insolação e competição com plantas daninhas de ecotipos de chapéu de couro (Echinodorus spp.) do Rio Grande do Sul. Pelotas, RS, 1998.

\begin{tabular}{|c|c|c|c|c|}
\hline Ecotipo & Pegamento & $\begin{array}{c}\text { Resistência } \\
\text { ao frio }\end{array}$ & $\begin{array}{l}\text { Resistência } \\
\text { à insolação }\end{array}$ & $\begin{array}{l}\text { Competição com } \\
\text { plantas daninhas }\end{array}$ \\
\hline 1 & 1,5 & 1,4 & 2,0 & 2,0 \\
\hline 2 & $1,0 \mathrm{i}^{*}$ & $1,2 \mathrm{i}$ & 2,0 & 2,0 \\
\hline 3 & $0,5 \mathrm{i}$ & $0,6 \mathrm{i}$ & $1,0 \mathrm{i}$ & $1,5 \mathrm{i}$ \\
\hline 4 & 1,5 & $0,8 \mathrm{i}$ & 2,0 & $1,5 \mathrm{i}$ \\
\hline 5 & $1,0 \mathrm{i}$ & $1,0 \mathrm{i}$ & 2,0 & 2,0 \\
\hline 6 & $3,0 \mathrm{~s}$ & $2,8 \mathrm{~s}$ & $2,5 \mathrm{~s}$ & $3,0 \mathrm{~s}$ \\
\hline 7 & 1,5 & $1,2 \mathrm{i}$ & 1,5 & 2,0 \\
\hline 8 & 2,0 & 1,8 & 1,5 & 2,0 \\
\hline 9 & 2,0 & 2,0 & 2,0 & 2,0 \\
\hline 10 & 2,0 & 2,0 & 2,0 & 2,0 \\
\hline 11 & 2,0 & 2,0 & $2,5 \mathrm{~s}$ & 2,0 \\
\hline 12 & $3,0 \mathrm{~s}$ & $2,6 \mathrm{~s}$ & 1,5 & $3,0 \mathrm{~s}$ \\
\hline 13 & $1,0 \mathrm{i}$ & 1,4 & 2,0 & $1,0 \mathrm{i}$ \\
\hline 14 & $1,0 \mathrm{i}$ & 1,8 & 2,0 & $1,0 \mathrm{i}$ \\
\hline 15 & 2,0 & 2,0 & $1,0 \mathrm{i}$ & 2,0 \\
\hline 16 & - & - & - & - \\
\hline Média & 1,7 & 1,6 & 1,8 & 1,9 \\
\hline $\mathrm{Dp}$ & 0,5 & 0,3 & 0,6 & 0,3 \\
\hline
\end{tabular}

* inferior ( i ) e superior ( s ) ao desvio padrão com significância em nível de $5 \%$ de probabilidade. ecotipos 2, 3, 4 e 5, provenientes de Porto Alegre, Santo Augusto, Sobradinho e Passo Fundo, RS, mostraram-se significativamente inferiores. O desaparecimento das folhas e a paralisação do crescimento foram observados nas plantas em 07/07 na área experimental e no habitat natural, pois a primeira geada ocorreu somente em 20/06, sendo 1997 um ano atípico em relação à média climática da região.

Quanto a resistência à insolação, os ecotipos 6 e 11, de São Gabriel e Alegrete, RS, respectivamente, mostraram-se significativamente superiores, enquanto os ecotipos respectivamente, mostraram-se inferiores (Tabela 2). De uma maneira geral, a planta não é muito resistente à insolação e ao solo seco, pois o sol forte resseca as folhas e as torna pouco resistentes, conforme informações de SILVA JUNIOR et al. (1994). Por outro lado, os ecotipos 6 e 12, provenientes de São Gabriel e Pelotas, RS, mostraram-se significativamente superiores na avaliação do pegamento e competição com plantas daninhas. No entanto, o aspecto pegamento está relacionado ao vigor das mudas, e existe uma variação inerente ao material. Os ecotipos 2 e 5 mostraram-se significativamente inferiores na avaliação do pegamento, enquanto os ecotipos 3, 13 e 14, provenientes de Santo Augusto3 e 15, de Santo Augusto e Mata, RS, Arroio Grande e Jaguarão, RS, apresentaram-se significativamente inferiores nos dois parâmetros avaliados, o que pode tratar-se de baixa adaptação para o cultivo.

Com relação ao início da brotação, observa-se na tabela 3 , que o ecotipo 4 , proveniente de Cruz Alta, RS, é precoce (média menos o desvio padrão), enquanto os ecotipos 2,5 e 13, provenientes de Porto Alegre, Passo Fundo e Arroio Grande, RS, são tardios. Nos demais ecotipos, os valores estiveram dentro do desvio padrão. O ecotipo 3, de Santo Augusto, RS, possui alto vigor da brotação, enquanto o ecotipo 14, de Jaguarão, RS, baixo vigor. Assim, destacaram-se os ecotipos provenientes de Cruz Alta e Santo Augusto, RS, como precocidade e vigor da brotação, respectivamente, embora o primeiro tenha sido transplantado apenas em fevereiro de 1997 e os demais entre novembro e dezembro de 1996.

O início do florescimento das plantas variou consideravelmente entre os ecotipos, sendo esse fato determinante para estipular a época de colheita das folhas de várias espécies (CASTRO \& CHEMALE, 1995). Assim, o ecotipo 4, de Cruz Alta, RS, é o mais precoce, enquanto os ecotipos 5, 13 e 14, provenientes de Passo Fundo, Arroio Grande e Jaguarão, RS, são tardios (Tabela 3). Pode-se, ainda, supor que 
Tabela 3- Início da brotação, início da floração, vigor da brotação ( $\mathrm{n}^{\circ}$ de folhas/inflorescência), antese, maturação da semente, peso da matéria seca (PMS) foliar de 16 ecotipos de chapéu de couro (Echinodorus spp.). Pelotas, RS, 1998.

\begin{tabular}{rcccccc}
\hline Ecotipo & $\begin{array}{c}\text { Início da } \\
\text { brotação } \\
\left(\text { dias }^{1}\right)\end{array}$ & $\begin{array}{c}\text { Início da } \\
\text { floração } \\
\text { (dias) }\end{array}$ & $\begin{array}{c}\text { Vigor da } \\
\text { Brotação }\end{array}$ & Antese & $\begin{array}{c}\text { Maturação } \\
\text { da se- } \\
\text { mente } \\
\text { (dias) }\end{array}$ & $\begin{array}{c}\text { PMS } \\
\text { foliar } \\
\text { (g) }\end{array}$ \\
\hline & & & & & & \\
1 & 250 & - & - & - & - & 0,14 \\
2 & $268 \mathrm{i}^{2}$ & - & - & - & - & 0,15 \\
3 & 210 & 297 & $4,5 \mathrm{~s}$ & 330 & 340 & 0,62 \\
4 & $170 \mathrm{~s}$ & $230 \mathrm{~s}$ & 9 & $240 \mathrm{~s}$ & - & 0,29 \\
5 & $285 \mathrm{i}$ & $425 \mathrm{i}$ & 6 & $435 \mathrm{i}$ & $442 \mathrm{i}$ & 0,26 \\
6 & 220 & 265 & 7 & 296 & 314 & $2,24 \mathrm{~s}$ \\
7 & $200 \mathrm{~s}$ & $240 \mathrm{~s}$ & 7 & $270 \mathrm{~s}$ & - & - \\
8 & 235 & 288 & 8 & 304 & 325 & 0,33 \\
9 & 220 & 300 & 6 & 315 & 320 & 0,46 \\
10 & 220 & 278 & 8 & 289 & 312 & 0,41 \\
11 & 210 & 270 & 8 & 299 & 322 & 0,42 \\
12 & 240 & 303 & 8,5 & 327 & 350 & 1,02 \\
13 & $260 \mathrm{i}$ & $390 \mathrm{i}$ & 7 & $400 \mathrm{i}$ & $435 \mathrm{i}$ & 0,16 \\
14 & 230 & $380 \mathrm{i}$ & $11 \mathrm{i}$ & $384 \mathrm{i}$ & $419 \mathrm{i}$ & 0,10 \\
15 & 210 & 278 & 8 & 299 & 320 & 0,63 \\
16 & - & - & - & - & - & - \\
Média & 230 & 304 & 7,5 & 324 & 355 & 0,51 \\
Dp & 27 & 55 & 1,5 & 50 & 47 & 0,52 \\
& & & & & & \\
\hline
\end{tabular}

${ }^{1}$ Período do transplante até o início da brotação, floração, antese, maturação da semente.

${ }^{2}$ inferior ( i ) e superior ( s ) ao desvio padrão com significância em nível de $5 \%$ de probabilidade.

maior precocidade e vigor na brotação podem estar relacionados com uma floração mais precoce, fato que realmente aconteceu, pois os ecotipos mais tardios foram menos vigorosos (ecotipo 14) e com início de brotação mais tardia (ecotipos 5 e 13). Os ecotipos 1 e 2, de Camaquã e Porto Alegre, RS, respectivamente, não floresceram, esse fato pode estar relacionado à falta de reservas na planta para realizar a floração, permanecendo apenas crescimento vegetativo, fato citado por SILVA JUNIOR $\boldsymbol{e} t$ al. (1994).

Os ecotipos 4 e 7, de Cruz Alta e São Vicente, RS, podem ser classificados como mais precoces com relação à antese, na qual a abertura das flores ocorreu 10 dias após o início da floração, sendo que, em média, esse período foi de 20 dias (Tabela 3). O ecotipo 7 pertence ao gênero Sagittaria e possui floração mais precoce e longa. Portanto, o ecotipo 4 pode ser classificado como preferencial para o cultivo pela precocidade de antese. Para a maturação das sementes, os ecotipos 5, 13 e 14, de Passo Fundo, Arroio Grande e Jaguarão, RS, respectivamente, apresentaram ciclo mais longo. Os demais ficaram dentro do desvio padrão para a maturação. Em média, o período da antese até a maturação da semente foi de 31 dias.

O ecotipo 6, proveniente de São Gabriel, foi aquele que apresentou o maior peso de matéria seca, sendo que os demais não se distinguiram do desvio padrão. Em média, o peso seco foliar foi $0,52 \mathrm{~g}$.

A análise de correlação mostrou que pegamento se correlaciona positiva e significativamente com resistência ao frio $(\mathrm{r}=0,88)$ e com competição com plantas daninhas $(r=0,82)$, enquanto que a resistência ao frio se correlaciona positivamente com competição com plantas daninhas $(\mathrm{r}=0,62)$. Portanto, devido à alta correlação da resistência ao frio, ao pegamento e competição com plantas daninhas, esse parâmetro, sem dúvida, deverá ser aquele preferencial na seleção de genótipos para o cultivo comercial. Por outro lado, a resistência à insolação não se correlacionou com nenhum dos outros parâmetros.

\section{b) Análise dos padrões fitoquímicos da planta}

A análise dos padrões fitoquímicos mostrou que os ecotipos apresentaram grande variabilidade através de análise cromatográfica dos extratos. Plantas da mesma espécie e subespécie apresentaram perfis cromatográficos bastante diferenciados (Figura 1). Esse resultado difere daquele encontrado por VAN WYK et al. (1995) que, trabalhando com a espécie Aloe ferox, mostrou uma composição química invariável, para os compostos químicos majoritários. Os ecotipos de Arroio Grande (13) e Jaguarão (14) apresentaram o maior número de manchas na análise cromatográfica, pertencentes à espécie $\boldsymbol{E}$. grandiflorus. Esse resultado pode indicar variabilidade química ou mesmo edafo-climática, pois os mesmos situam-se na região sul do estado, em condições ambientais semelhantes. Por outro lado, o ecotipo de Pelotas (12), da espécie $\boldsymbol{E}$. uruguayensis, mostrou uma composição química semelhante a $\boldsymbol{E}$. grandiflorus.

Todas as amostras apresentaram um grupo básico de 6 manchas, na comparação cromatográfica dos extratos, usando como revelador luz ultravioleta $366 \eta m$ (dados não apresentados). Por outro lado, os ecotipos 13 e 14 apresentaram praticamente o mesmo perfil cromatográfico, através dos dois 


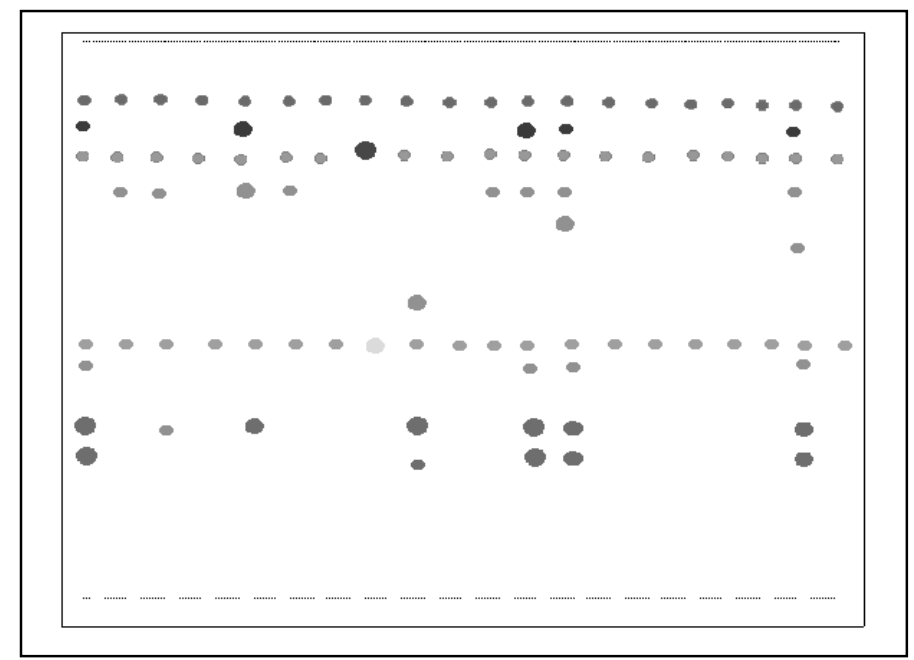

$\begin{array}{llllllllllllllllll}1 & 2 & 3 & 4 & 5 & 6 & 8 & 9 & 10 & 11 & 12 & 13 & 14 & 15 & 16 & 6_{\mathrm{N}} & 11_{\mathrm{N}} 12_{\mathrm{N}} 13_{\mathrm{N}} 16_{\mathrm{N}}\end{array}$

Figura 1 - Perfil cromatográfico em camada fina delgada no revelador vanilina sulfúrica de 15 ecotipos de chapéu de couro (Echinodorus spp). Pelotas, RS, 1998 $\mathrm{N}$ - Planta nativa.

métodos de revelação. Os ecotipos Porto Alegre, São Gabriel e Alegrete apresentaram o mesmo perfil cromatográfico, ou seja, parecem ter composição química semelhante, assim como os ecotipos Cruz Alta, Sobradinho, Mata e Torres, através dos métodos de revelação em vanilina sulfúrica, embora sejam provenientes de diferentes regiões do estado (Campanha, Planalto Médio e Depressão Central).

Quando foram analisados materiais provenientes de áreas de ocorrência natural e aqueles cultivados em área experimental, os materiais mostraram composição química semelhante, ou seja, mesmo perfil cromatográfico. Portanto, as plantas cultivadas com adubação orgânica mostram uma composição química inalterada e podem ser exploradas comercialmente sem risco de perda da capacidade fitoterápica.

\section{CONCLUSÕES}

A espécie predominante no Rio Grande do Sul é a Echinodorus grandiflorus. Os ecotipos de Cruz Alta e de São Gabriel são recomendados para cultivo como precocidade e produção de matéria seca, respectivamente. Os ecotipos de Arroio Grande e Jaguarão são recomendados para cultivo pela composição química mais numerosa.

\section{REFERÊNCIAS BIBLIOGRAFIA}

ALMEIDA, E.R. Plantas medicinais brasileiras: conhecimentos populares e científicos. São Paulo : Hemus, 1993. 341p.
ARORA, R.K., ENGELS, J.M.M. Genetic resources in the medicinal and aromatic plants: their conservation and uses. Wageningen : International Society for Horticultural Science, 1993. p.101-106.

CASTRO, L.O., CHEMALE, V.M. Plantas medicinais, codimentares e aromáticas: descrição e cultivo. Guaiba : Agropecuária, 1995. 196p.

CORREIA JUNIOR, C., MING, L.C., SCHEFFER, M.C. Plantas medicinais. 2 ed. Jaboticabal : FUNEP, 1994. 162p.

CORREA, M.P. Dicionário de plantas úteis do Brasil e das exóticas cultivadas. Rio de Janeiro : Ministério da Agricultura/IBDF, 1984. v.6.

FOSTER, S. Medicinal plant conservation and genetic resources: examples from the temperate Northern Hemisphere. Wageningen: International Society for Horticultural Science, 1993. p.67-74.

HAYNES, R.R., HOLM-NIELSEN, L.B. The alismataceae. Flora Neotropica - Monograph 64. New York: The New York Botanical Garden, 1994. 109 p.

MANNS, D., HARTMANN, R. Echinodol: A new cembrene derivate from from Echinodorus grandiflorus. Planta Med, v.59, p.465-467, 1993.

OLIVEIRA, F., AKISSUE, G. Fundamentos de farmacobotânica. Rio de Janeiro : Atheneu, 1989. Cap.12, p.148.

SILVA, S.M. Aspectos da fenologia e da reprodução sexuada da arnica (Lycnophora pinastes Mart.) - Asteraceae. Lavras-MG, 1993. 25p. Dissertação (Mestrado em Agronomia) - Curso de Pós-graduação em Agronomia, UFL, 1993.

Silva JR., A.A., VIZZOTTO, V.J., GIORGI, E., et al. Plantas medicinais, caracterização e cultivo. Florianópolis : EPAGRI, 1994. 71p. (EPAGRI. Boletim Técnico, 68)

SILVA JR., A.A., VIZZOTTO, V.J. Plantas medicinais, aromáticas e fitoprotetoras. Agropecuária Catarinense, Florianópolis, v.9, n.1, p.5-8, 1996.

SIMÕES, C.M.O., MENTZ, L.A., SCHENKEL, E.P., $\boldsymbol{e}$ t al. Plantas medicinais da medicina popular do Rio Grande do Sul. 4 ed. Porto Alegre : Universitária, 1995. 174p.

STAHL, E. Thin-layer chromatography - a laboratory handbook. 2 ed. New York: Springer-Verlag, 1969. 600p.

TANAKA, C.M.A., SIRRAGIOTTO, M.H., ZUKERMANSCHPECTOR, J., et al. A cembrane from Echinodorus grandiflorus. Phytochemistry, v.44, n.8, p.1457-9, 1997.

VAN WYK, B.E., VAN RHEEDE-VAN OUDTSHOORN, M.C., SMITH, G.F. Geographical variation in the major compounds of Aloe ferox leaf exsudate. Planta Med, v.61, n.3, p.250-253, 1995.

VIEIRA, R.F., SKORUPA, L.A. Brazilian medicinal plants gene bank. Wageningen : International Society for Horticultural Science, 1993. p.51-58. 